auf 4 Aeq. Chrom enthalten sind, so scheint die Formel $\mathrm{C}^{14} \mathrm{H}^{8} \mathrm{O}^{7}$ der Kaffeegerbsäure oder ein Multiplum derselben dadurch bestätigt. Concentrirte Salpetersäure zu einer conc. wässerigen Lösung der Kaffeegerbsäure gesetzt, bewirkt eine so stürmische Gasentwickelung, dass die Masse aus dem Gefinsse geschleudert werden kann. Bei Anwendung von verdünnterer Säure erhält man Oxalsiuure, frei von jeder Beimengung. Das Destillat enthält grosse Mengen Blausäure. Es wurde das Destillat auf Zusatz von salpetersaurer Silberlösung ganz erfüllt mit weissen Flocken, 0,4023 Grm. des Nicderschlags liessen 0,3232 Silber oder 80,3 Proc. Das Cyansilber fordert 80,6 Proc. Silber. Die Bildung von Blausäure bei der Einwirkung von Salpetersäure auf stickstofffreie Körper wurde schon liingst beobachtet, z. B. bei ätherischen Oelen von Sobrero, aber es ist keine Substanz bekannt, die so auffallend grosse Mengen von Blausïure liefert, wie die Kaffeegerbsäure. Das Fett der Kaffeebohnen besteht aus einem flüssigen und festen Theile. In letzterem Theile hat Rochleder in einiger Menge eine fette Säure gefunden, deren $\mathrm{Zu}$ sammensetzung im Hydratzustande ganz nahe mit der Palmitinsiiure übereinstimmte. Ebenso enthielt das Silbersalz dieselbe Menge Silber wie die Silberverbindung der Palmitinsäure. Dass auch andere feste fette Säuren diese Sïure begleiten, geht schon daraus hervor, dass Kochleder die Palmitinsäure durch öfteres Umkrystallisiren zu reinigen suchte. Eine solche leichter lösliche Süure gab die Zusammensetzung wie folgt. v. $P$ ay $r$ fand in $0,236 \mathrm{Grm}$. Substanz 0,626 Grm. Kohlensiure und 0,258 Grm. Wasser, was nahe der Formel $\mathrm{C}^{24} \mathrm{H}^{24} \mathrm{O}^{4}$ entspricht. Möglich ist es, dass auch diese Substanz ein Gemenge ist. Es wird dies hier nur èwähnt, weil Stenhouse Zweifel in Beziehung auf Rochleders Untersuchung der Kaffeebohnen äussern zu müssen glaubte. Nächstens wird Rochled er Gelegenheit nehmen, seine Zweifel an der Arbeit Stenlsou se's zu äussern. (Sitz.-Ber. der Akad. d. Wissensch. Bd. 24. (hem. C'entrbl. 1858. No. 5.)

$B$.

\title{
Das Kupferoxydammoniak, ein Lösungsmittel für Pflanzenfaser.
}

Ed. S chweizer beobachtete, dass eine Flüssigkeit, die er beim Aufösen des basisch-unterschwefelsauren Kupferoxyds von $\mathrm{Heeren} 4 \mathrm{CuO}, \mathrm{S}^{2} \mathrm{O}^{5}$ in Ammoniak erhielt, die Eigenschaft habe, Baumwolle zu lösen. Das 
Verhalten der Flüssigkeit liess erkennen, dass sich beim Auflösen dieses Salzes in Ammoniak auch Kupferoxydammoniak gebildet hatte, weil sich aus der Flüssigkeit Krystalle von unterschwefelsaurem Kupferoxydammoniak $2 \mathrm{H}^{3} \mathrm{~N}+\mathrm{CuO}, \mathrm{S}^{2} \mathrm{O}^{5}$ abgesetzt hatten. Schweizer fand dann weiter, dass die Lösung von basisch-schwefelsaurem Kupferoxyd in Ammoniak sich eben so verhailt und leichter bereiten lässt. Als Schw eizer gereinigte Baumwolle mit jener ersteren Flüssigkeit übergoss, nahm dieselbe eine gallertartige schliipfrige Beschaffenheit an, die Fasern gingen auscinander und verschwanden, und nach einigen IJurcharbeiten mit einem Glasstabe hatte sich das Ganze in eine schleimige Flïssigkeit verwandelt. Dabei findet nicht die geringste Wairmeentwickelung statt. Hat man eine nicht hinreichende Menge der Flüssigkeit angewendet, so bleibt ein Theil der Fasern noch sichtbar; setzt man dann aber einen Ueberschuss der Lösung hinzu und schüttelt um, so erhält man eine beinahe klare blaue Lösung, die sich, nachdem sie mit Wasser verdünnt worden ist, filtriren lïsst.

Uebersättigt man die filtrirte Lösung mit Salzsäure, so cntsteht ein voluminöser weisscr Niederschlag, der auf einem Filter gesammelt, ganz das Ansehen von feuchtem Thonerdehydrat besitzt.

Es scheint diese Substanz zwar desorganisirte, aber in ihrer chemischen Natur nicht wesentlich veränderte Cellulose zu sein.

Vertheilt man den durch Auswaschen vollständig von Salzen befreiten gallertartigen Niederschlag in Wasser, setzt Jodkalium und nachher etwas Chlorwasser hinzu, so färbt sich die Substanz braun, ein Beweis, dass dieselbe weder Stärke noch ein stärkehaltiger Körper ist.

Beim Eintrocknen auf dem Wasserbade schwindet jener Niederschlag stark zusammen und hinterlässt eine hornartige, durchscheinende, spröde Masse, welche Aehnlichkeit mit eingetrocknetem Kleister hat, jedoch keinerlei Geschmack besitzt und zwischen den Zühnen nicht klebt An der Luft erhitzt, verbrennt die Substanz, ohne einen Rückstand zu lassen.

Ganz auf gleiche Weise wie Baumwolle, verhalten sich Papier und Leinewand zu der Kupferoxydammoniaklösung, nur werden sie etwas langsaner als die Baumwolle aufgelöst.

Auch auf einige thierische Gebilde erstreckt sich die lösende Kraft des Kupferoxydammoniaks. Seide löst sicb 
in der bezeiclneten Flüssigkeit noch schneller auf als Baumwolle: aus der filtrirten klaren Lösung wird durch Säure ebenfalls ein gallertartiger Körper ausgeschieden. Wolle wird nur in der Wärme vollstïndig gelöst. Haare werden nach und nach von der Flüssigkeit zerstört, ohne dass eine vollständige Autösung statt tindet. Thierische Blase quillt darin im Anfange bloss auf, löst sich aber nach einiger Zeit ebenfalls. Auffallend ist. dass die der Pflanzenfaser so nahe stehende Stärke von der Flüssigkeit nicht gelöst wird. Beim Erhitzen bildet sich ein schön blauer Stärkekleister, während die Flüssigkeit beinahe entfirbt wird. (Vierteljahrsschr. der naturf. Gesellsch. zu Zilrich. 1857. - Chem. Centrbl. 1858. No. 4.) L'.

\section{Huanokin, eine neue Base der Chinarinde.}

Unter dem Namen China de Huanuco plena kommt in Handel seit etwa 10 Jahren cine (hinarinde vor, die im Norden von Lima in den Wäldern von Huanuco eingesammelt wird und, wie es scheint, von Cinchona nitida abstanmt. Sic hat eine solche Aehnlichkeit mit der China regia plana (Chinc de Calisaya), dass man sie sehr genau betrachten muss, um sie damit nicht zu verwechseln. Sie unterscheidet sich von der China Calisaya durch folgende Verhältnisse :

1) Ihre Textur ist viel loser und die Fasern sitzen in dern Derma viel fester, so dass sie sich nicht leicht daraus loslösen lassen. Die Fasern sind kurz und daher hat die linde einen kurzfaserigeu Bruch.

2) Die Stücke sind 6 bis 10 Millineter dick, meistens viel schmaler, selten parallel, gewöhnlich nach einem Ende keilförmig verschmälert und zuweilen auch nach beiden Enden, wodurch die Stücke entweder eine schlanke, keilförmige oder lang gezogene ovale Gestalt haben.

3) Die Oberfliche des Dermas zcigt zwar ähnliche Vertiefungen, wie die bei der China Calisaya charakteristischen Fingerfurchen, aber sie sind niemals so tief, nur in eiuzelnen Fällen scharf gerändert und niemals geschlossen, sondern verlaufen alle unregelmässig länglich und schmaler werdend, um in andere überzugehen.

4) Nur an wenigon Stücken sitzt noch das Periderma auf, und dieses ist dann dünn, weich, mannigfach zerkliiftet und durch verschiedene Flechten und Pilzbildungen ungleich gefürbt.

Hiernach ist die China Huanuco plana leicht zu 